\title{
Rejoinder to the Kyle Swan Response
}

\section{J. C. Lester}

Contra critical rationalism, the response begins by referring to "the variety of internalist and externalist versions of foundationalism" (Liberty, December 2002). But it makes no attempt to explain or defend any of them. Hence, no further criticism is due here. The response then argues that, "The critical rationalist method seems to suggest that Lester's extreme compatibility thesis is probably false" because - quoting Escape from Leviathan (EfL) — "bold universal theories might be false, and probably are" and yet "he doesn't think the thesis is probably false". And so this is, by implication, an inconsistent belief. But the Compatibility Thesis (CT) is not one of the "bold universal theories" of science. The review and the response appear, at times, to assume that the CT is a bold universal theory about the perfect compatibility of applying the relevant conceptions, or theories, of rationality, liberty, welfare, and anarchy. Then, at other times, they assert that it is not bold at all but merely about definitions designed to be compatible. In fact, the CT asserts both that there are no theoretical incompatibilities among relevant and plausible versions of the theories, and that there are no actual long-term, systemic, and practical conflicts among applying them. That is still a bold theory (perhaps even most libertarians would disagree with it), but it's not a universal thesis of perfect compatibility. And if it were good practice to reject a theory just because of its boldness, then all scientific theories would be immediately rejected without even trying to produce a falsification. In any case, as stated in the reply to the review, anyone's mere beliefs are irrelevant to the truth of objective theories and the soundness of objective arguments.

The response reasserts that "questions regarding the logical compatibility of ideas depend upon one's definitions of those ideas". Therefore, it is here reasserted that EfL is defending the relevance and practical compatibility of certain theories. This cannot be reduced to whether certain "definitions" are logically consistent. The response insists that "in order to deal with certain practical problems, Lester must fiddle with" the "definitions". It is not a "fiddle with" the "definitions" but various arguments that explain that applying the libertarian conception of liberty-in-itself, as EfL theorises and defends it, "isn't always compatible with absolute private property rights". It is hard to understand why the response sees EfL's answer to David Friedman's apparent paradox of absolute property rights as mere definitionfiddling rather than a serious philosophical answer.

On the reply to Rothbard on this issue, the response holds that applying EfL's conception of liberty "isn't possible here unless the property rights of the others are compromised or modified in some way". That is approximately correct. When there are inevitable practical clashes of liberty, as EfL explains will happen, normal understandings of libertarian property rights have to be modified to maximise liberty (but, more strictly, fully libertarian-derived property rights can only be respected in this way). The response continues, "But alternatively, the other's absolute control of their property isn't possible here unless the individual liberty of the first person is compromised". Why should he have such absolute control if it clashes with liberty? The response implies that absolute control is somehow libertarian. EfL explains why it isn't.

As the response observes, with EfL's "definition" (theory) "it is not generally possible to secure for someone the absence of [initiated] impositions", and so we can only maximise liberty (minimise initiated impositions) as far as is practical. The response insists that this shows that liberty is "compromised". It is true that we have to make 'compromises' in terms of absolute individual liberty in order to maximise overall individual liberty. But, as perfect liberty for all people at all times is simply not an option, it is hard to see why the response assumes liberty as a goal to be aimed at has been "compromised". What other aim has compromised liberty?

The response also assumes that minimising initiated impositions (maximising liberty) is "a retreat from the compatibility thesis as $[E f L]$ initially formulated it. It amounts to an admission that liberty as absence of [initiated] impositions is not 'in practice and in the long term' compatible with general welfare and private property". Perhaps no statement is so perfectly unambiguous that it can never be misunderstood. But why does the response assume that EfL puts forward a thesis involving everyone's having perfect liberty-in-itself when it argues throughout that such liberty can only be maximised in practice? Or if one assumes that EfL is "initially" committed to perfect liberty, then why not also assume that it is committed to perfect welfare (having all of your unimposed wants satisfied) 
and perfect private property (with never any interference or compromise) - both of which are also not practical - and then assert that EfL retreats from them too? The CT is 'only' that all three are maximised together. Hence, there is no "retreat". The maximalist theory appears to be bolder than other versions of libertarianism; but it is not so bold as to be perfectionist.

It is misleading to say that "Non-anarchists, non-libertarians, even political liberals agree with Lester that [initiated] impositions should be minimized". Those groups are usually fully prepared to allow initiated impositions in order to achieve "other values in the political realm". They are not in any way aiming at a "minimal level" of initiated impositions; and they are often even reckless or oblivious concerning liberty. The response then states that it is "misleading for [EfL] to claim that [it is] offering an account of the objective compatibility of all these values". But EfL's reconciliation concerns only certain objective theories of liberty, welfare, and anarchy and their objective compatibility in practice. It does not at any time present or defend these as "values" that ought to be held. Why is its approach not objective?

When the reply to the review says that liberty-in-itself as the absence of initiated impositions is incompatible with absolute control of private property, it means to imply in Friedman's and Rothbard's type of examples; not in every possible instance. It is still hard to see what this has to do with the response's discussion of intellectual property, where copyrights and patents still appear to be confused. The response supposes that if the independent later inventor of an "idea" can have the "copyright" (surely, patent) and "absolute control", then EfL agrees that "the liberty as absence of [initiated] impositions of the former person is compromised". But under EfL's theory of intellectual property both the first inventor and the independent later inventor of an idea would, in principle, be entitled to a libertarian share of the patent (until such time as, counterfactually, that thing would likely have been invented by some third person). The response then asserts that "in the case of patents, the liberty of others as Lester defines it is expanded as the patent holder's control of his property is compromised". This is hard to interpret clearly without a more-detailed explanation. But there is no initiated imposition on other people with a patent that fits EfL's theory. And so "the liberty of others ... is [not] expanded as the patent holder's control of his [intellectual] property is compromised". It is the benefits of others that are expanded at the patent holder's initiatedly imposed expense.

Finally, the response reasserts that "given [EfL's] definition of what rationality is and its purported connection to welfare as want-satisfaction, [the reply is] committed to the implausible claim that the person [it] imagined has enhanced his welfare by drinking the gasoline". This is a mistake. The rationality theory is that people try to obtain what they think it best to have at that moment and in the perceived circumstances. The welfare theory is that people are better off to the extent that they obtain more of what they want overall. Drinking the gasoline by mistake will obviously decrease this overall want-satisfaction. Thus, there is no implication that the satisfaction of such mistaken wants contributes to such overall welfare.

Doubtless, there is still much confusion on both sides about exactly what the other side is arguing on many of these issues. But perhaps at least some of the issues have been somewhat clarified. It is worth repeating that a far clearer and highly concise version of this general philosophical theory of libertarianism is now available. ${ }^{1}$ Before tackling $E f L$, or subsequent books, ${ }^{2}$ it is probably best to consult that for an overview.

(October 2002; revised January 2022.)

\footnotetext{
${ }^{1}$ See Lester, J. C. 2022. "Eleutherological-Conjecturalist Libertarianism: a Concise Philosophical Explanation", PhilPapers: https://philpapers.org/rec/INDNLA.

${ }^{2}$ See relevant chapters in Lester, J. C. Explaining Libertarianism: Some Philosophical Arguments (Buckingham: The University of Buckingham Press, 2014) and, to a lesser extent, Arguments for Liberty: A Libertarian Miscellany (Buckingham: The University of Buckingham Press, [2011] 2016).
} 